Assessment criteria were classified into 4 levels including starting level, good level, very good level and excellent level PCUs depending on the ability of PCUs practices.

Conclusion PCUs' staff could provide the OHS following such standard which address not only health services for community workers, but also for health workers (PCUs staff) and vulnerable populations who affect from environmental pollutions in the community (if have).

\section{FINDING AT-RISK, LOW WAGE WORKERS IN COMMUNITY HEALTH CENTRES IN THE US}

Linda Forst*, Liza Topete, Joseph Zanoni, Lee Friedman. University of Illinois at Chicago School of Public Health, Chicago, Illinois, USA

\subsection{6/oemed-2018-ICOHabstracts.448}

Introduction The 'working poor' bear an inequitable burden of work-related injuries, illnesses, and fatalities. They often obtain healthcare in community health centres (CHCs) and do not report work-relatedness. The aim was to determine whether the $\mathrm{CHCs}$ are a high yield venue for reaching low wage workers and to examine low-wage workers' experience with Workers' Compensation (WC).

Methods A mixed methods survey was conducted in rural and urban CHCs.

Results 50 interviews among largely Latino and African-American workers from 11 different sectors and 41 different job titles, most of them associated with low wages, showed: $55 \%$ had experience with a work-related; all knew the employer was responsible for health care. Most respondents did not access their full rights. The major reporting barriers were fear of job loss, fear of deportation, and personal stoicism. Knowing one's rights and finding an advocate were noted facilitators of reporting.

Discussion Lack of reporting circumvents the use of WC, depriving these patients of optimal healthcare and limiting access to medication, rehabilitation, disability compensation and wage replacement. Furthermore, it shifts the burden of fee reimbursement to CHCs, federal programs, and the worker-patients. Fear of job loss and deportation of adds to the list of rights infringement and root causes of health inequities. Increasing knowledge of labour laws and health and safety protections should improve health outcomes. Lowwage, at-risk, and formerly injured workers were easy to find in a CHC, suggesting that this as a venue for training of workers and of primary care providers. Policy initiatives to protect these workers are critical.

\section{EFFECTIVENESS EVALUATION IN OCCUPATIONAL HEALTH}

Stefano Mattioli*. Department of Medical and Surgical Sciences, University of Bologna, Italy

\subsection{6/oemed-2018-ICOHabstracts.449}

Aim of special session To provide elements useful to evaluate preventive interventions in occupational health and to disseminate its results

Presenters: ${ }^{1}$ Stefano Mattioli, ${ }^{1}$ Stefania Curti, ${ }^{2}$ Jani H Ruotsalainen, ${ }^{3}$ Henk $\mathrm{F}$ van der Molen

${ }^{1}$ Department of Medical and Surgical Sciences, University of Bologna, Italy
${ }^{2}$ Cochrane Work, Finnish Institute of Occupational Health, Kuopio, Finland

${ }^{3}$ Academic Medical Centre, University of Amsterdam, Department: Coronel Institute of Occupational Health, Amsterdam Public Health research institute, Amsterdam, The Netherlands

\section{2a PREVENTIVE INTERVENTIONS: TO EVALUATE OR NOT TO EVALUATE?}

S Mattioli. Department of Medical and Surgical Sciences, University of Bologna, Italy

10.1136/oemed-2018-ICOHabstracts.450

The production of studies regarding the evaluation of the effectiveness of preventive interventions is still modest, especially in comparison with the production of effectiveness studies in the clinical field. This can be at least partly due to the real difficulty to evaluate the effects of preventive actions on injuries at work and on occupational diseases, which can be affected by many other causal factors, including regulatory actions, periods of economic and employment crisis, technological innovations, changes in the distribution of risk factors in the population.

Such complexity must be carefully considered when the researcher approaches the effectiveness evaluation in the occupational health field and, to do so, the evaluation of effectiveness should be planned before to start with the intervention.

Three elements have to be clearly defined:

1. the objective of the assessment;

2. the intervention that the researcher wants to evaluate; and

3. the outcome to be measured as effect of the intervention itself.

At the same time, it should be ensured whether the considered preventive intervention has already been studied. This could be performed searching the literature, in order to find the information relevant to the problem that needs to be addressed.

Finally, before promoting the intervention - on the basis of technical knowledge and availability of the tools, considering also economical and time concerns - it is necessary to choose the type of study design that is more appropriate and feasible to assess the effectiveness of the intervention: it has to be considered the growing evidence coming from studies like case-report, cross-sectional, before-after, controlled before-after, interrupted time series, case-control, cohort and randomised (individually or by cluster) controlled trials.

\section{2b HOW TO EXECUTE AN EFFECTIVE SEARCH ON PUBMED BEFORE CARRYING OUT A PREVENTIVE INTERVENTION}

\section{S Curti. Department of Medical and Surgical Sciences, University of Bologna, Italy}

\subsection{6/oemed-2018-ICOHabstracts. 451}

Well-defined search strategies can provide efficient and effective tools to help addressing specific research questions in the field of evidence-based prevention in occupational health. The planning of a preventive intervention is a fundamental process for the evaluation of the effectiveness of the intervention. The first step is to explore the scientific literature to retrieve all 